NOTE

\title{
Parasites in the inner ear of harbour porpoise: cases from the North and Baltic Seas
}

\author{
Maria Morell ${ }^{1, *}$, Kristina Lehnert ${ }^{2}$, Lonneke L. IJsseldijk ${ }^{3}$, Stephen A. Raverty ${ }^{1,4}$, \\ Peter Wohlsein ${ }^{5}$, Andrea Gröne ${ }^{3}$, Michel André ${ }^{6}$, Ursula Siebert ${ }^{2}$, \\ Robert E. Shadwick ${ }^{1}$
}

\author{
${ }^{1}$ Zoology Department, University of British Columbia, Vancouver, British Columbia V6T1Z4, Canada \\ ${ }^{2}$ Institute for Terrestrial and Aquatic Wildlife Research, University of Veterinary Medicine Hannover, 25761 Büsum, Germany \\ ${ }^{3}$ Department of Pathobiology, Faculty of Veterinary Medicine, Utrecht University, 3584 CL Utrecht, The Netherlands \\ ${ }^{4}$ Animal Health Center, Ministry of Agriculture, Abbotsford, British Columbia V3G2M3, Canada \\ ${ }^{5}$ Department of Pathology, University of Veterinary Medicine Hannover, 30559 Hannover, Germany \\ ${ }^{6}$ Laboratori d'Aplicacions Bioacústiques, Universitat Politècnica de Catalunya, BarcelonaTech (UPC), \\ 08800 Vilanova i la Geltrú, Spain
}

\begin{abstract}
Peribullar sinuses of harbour porpoises Phocoena phocoena are parasitized with high prevalence by the nematode Stenurus minor. The effect of $S$. minor on the hearing ability of this species is still undetermined. Here, we review the occurrence of $S$. minor in the inner ear of harbour porpoises recovered from strandings in the North and Baltic Seas. In particular, we present the results from ears collected in German and Danish waters from 2002 to 2016 and from Dutch waters from 2010 to 2016 . While the prevalence of $S$. minor in pterygoid and peribullar sinuses and tympanic cavity was high in harbour porpoises (66.67\% in our cases), its prevalence in the cochlea was rare. Only 1 case out of 129 analysed by either histology, electron microscopy or immunofluorescence showed the presence of a nematode parasite morphologically consistent with $S$. minor at the most basal portion of the right cochlea. This individual also had severe haemorrhage along the right cochlear spiral, which was likely caused by ectopic $S$. minor migration. Although this animal might have had impaired hearing in the right ear, it was otherwise in good body condition with evidence of recent feeding. These findings highlight the need to study the effect of parasites on hearing, and other pathological changes that might impair appropriate processing of acoustic information.
\end{abstract}

KEY WORDS: Harbour porpoise $\cdot$ Phocoena phocoena $\cdot$ Nematode $\cdot$ Stenurus minor Inner ear Parasites $\cdot$ Cochlea $\cdot$ Haemorrhage

\section{INTRODUCTION}

Cetaceans and, in this particular case, harbour porpoises Phocoena phocoena, rely on hearing for vital activities, and any perturbations to sound perception can have significant impacts on their survival. Harbour porpoise cranial sinuses, and specifically peribullar sinuses, are parasitized by the

\footnotetext{
*Corresponding author: morell@zoology.ubc.ca
}

nematode Stenurus minor (Metastrongyloidea: Pseudaliidae), Kühn, 1829 with high prevalence (Deliamure 1955, Arnold \& Gaskin 1975, Brosens et al. 1996, Faulkner et al. 1998, Siebert et al. 2001, 2006, Kijewska et al. 2003, Lehnert et al. 2005, 2014). At present, the effect of $S$. minor on the hearing ability of harbour porpoises is still controversial.

() The authors 2017. Open Access under Creative Commons by Attribution Licence. Use, distribution and reproduction are unrestricted. Authors and original publication must be credited. 
Parasite infection could negatively affect hearing (Kijewska et al. 2003) and potentially contribute to mass strandings (Dailey \& Walker 1978). However, $S$. minor infection could also be less important in terms of clinical disease and mortality, as it has been found in otherwise presumably healthy by-caught animals. Mild inflammatory reaction of the soft tissue lining the tympanic cavity (i.e. place where middle ear ossicles are located) was associated with these parasites in a few strandings (Siebert et al. 2001). Although $S$. minor was present in the tympanic cavity, its occurrence in the inner ear was suspected by Kijewska et al. (2003) and to our knowledge, has not been shown conclusively in prior studies.

Here, we review the occurrence of $S$. minor in the inner ear of harbour porpoises recovered from strandings in the North and Baltic Seas. In particular, we present the results from ears collected in German and Danish waters from 2002 to 2016 and from Dutch waters from 2010 to 2016.

\section{MATERIALS AND METHODS}

\section{Samples and procedures}

The harbour porpoises in this study were submitted for necropsy to (1) the University of Veterinary Medicine Hannover in Germany, or (2) the Faculty of Veterinary Medicine (Utrecht University) in The Netherlands. The animals were not killed for the purpose of this study, but were found dead or were by-caught in Dutch, German and Danish waters of the North and Baltic Seas. The ears were collected from post mortem case material as part of an investigation into the cause of death, and analysed following different techniques depending on their origin.

\section{Germany (coastline of Schleswig-Holstein) and Denmark}

Both tympano-periotic complexes (TPCs) from 34 porpoises and 1 TPC from 3 porpoises ( $n=71$ ears in total) were fixed in $10 \%$ neutral buffered formalin, following the protocols described by Siebert et al. (2001). The TPCs of 21 animals were decalcified in $0.27 \mathrm{M}$ disodium ethylenediaminetetraacetic acid (EDTA) for approximately $7 \mathrm{wk}$, dehydrated in a graded ethanol series and embedded in celloidin as described previously (Jepson et al. 2006). The tissue was then sectioned serially $(20 \mu \mathrm{m})$ parallel to the modiolus, giving a total of about
800-1200 sections per ear. Every tenth section was stained with haematoxylin and eosin (HE). The cochlear area of the TPCs of 13 individuals was cut into $2 \mathrm{~mm}$ slices using a diamond band saw, decalcified in $0.27 \mathrm{M}$ EDTA for approximately 3 to $4 \mathrm{wk}$ and subsequently embedded in paraffin wax according to standard laboratory procedures. Tissue sections were cut at $3 \mu \mathrm{m}$ thickness and stained with HE.

\section{The Netherlands}

Since 2010, 58 inner ears from 38 harbour porpoises have been analysed. In all cases, post mortem examination was undertaken at the faculty of Veterinary Medicine, Utrecht University, according to protocols (Kuiken \& García Hartmann 1993). As part of the investigation, oval and round windows of both inner ears were perfused with $10 \%$ neutral buffered formalin (Morell \& André 2009).

The periotic bone surrounding the cochlea was decalcified using either $14 \%$ EDTA tetrasodium salt (Morell et al. 2017) or $\mathrm{RDO}^{\circledR}$ according to a previously optimized protocol (Morell et al. 2009).

The prevalence of parasites in the inner ear could be determined during the dissection while the cochlea was processed for immunofluorescence $(\mathrm{n}=$ 13) and scanning electron microscopy (SEM, n = 39), among other techniques.

\section{SEM}

Decalcification of the periotic bone was stopped when the vestibular scala and the stria vascularis of the cochlea were visually apparent. The cochlea was subsequently dissected, dehydrated in a graded ethanol series, critical point dried and coated with gold-palladium or platinum-palladium (Morell et al. 2015, 2017). The samples were evaluated with a Hitachi S-3500N SEM at the Institute of Marine Sciences, Spanish National Research Council, Spain, or with an S-4700 SEM at the University of British Columbia (UBC) Bioimaging Facility, Canada.

\section{Histology}

One sample from The Netherlands (left ear from UT 1317) was processed for histology. The periotic bone was completely decalcified by using $14 \%$ EDTA for $51 \mathrm{~d}$. 
Tissues were dehydrated through a graded series of alcohols to xylene using an automated tissue processor (Tissue Tek), embedded in paraffin, sectioned at $5 \mu \mathrm{m}$ and 3 consecutive sections retained every $100 \mu \mathrm{m}$. The slides were stained with HE.

\section{Nematode sampling}

Parasites were isolated from cranial sinuses and tympanic bullae, cleaned and preserved in 70-90\% ethanol (or in $10 \%$ neutral buffered formalin for individual UT 1317). Prevalence (Bush et al. 1997) and level of parasitic infection was determined macroscopically and semiquantitatively during necropsy as: none (no parasites observed), mild, moderate or severe (Siebert et al. 2001, Lehnert et al. 2005). Nematodes were cleared in glycerol or lactophenol and identified based on morphological characteristics according to the scientific literature (Arnold \& Gaskin 1975).

\section{RESULTS}

Examination of the tympanic cavity, peribullar and pterygoid sinuses during necropsy from all samples combined revealed 43 ears of porpoises with no parasites, 19 cases of mild, 31 cases of moderate and 36 cases of severe parasite infection.

Investigation of 71 inner ears collected from harbour porpoises recovered from Germany and Denmark did not identify Stenurus minor, whereas, in 1 case out of 58 ears analysed from The Netherlands, the right ear from a juvenile male harbour porpoise (UT 1317) presented with a parasite morphologically consistent with S. minor in the cochlea. Because of its significance, we will address in detail this particular case below.

The index case, individual UT 1317, was by-caught in a gillnet in Dutch waters on 3 July 2014. Approximately $15 \mathrm{~h}$ elapsed between the time of net deployment, retrieval, collection of the entangled animal and ear perfusion. Gross examination revealed a harbour porpoise in moderate to good nutritive condition. Externally, small sharp incisions were present bilateral on pectoral fins, fluke and the dorsal side of the tailstock, and linear imprints on the rostrum were observed; all external findings were consistent with by-catch. The animal showed signs of very recent feeding prior to death, based on both partly digested and undigested prey present in the stomach and undigested sandeels Ammodytes tobianus in the oral cavity and oesophagus. The lungs had severe bilateral oedema and mild bilateral nematodiasis, with moderate verminous pneumonia confirmed by histopathology. The gross and microscopic findings were consistent with entanglement and asphyxiation (Moore et al. 2013). In addition, the animal had generalized lymphadenopathy. Severe aggregates of parasites were also found in both peribullar cavities, and nematodes were morphologically consistent with S. minor. Chronic enteritis and subacute interstitial nephritis were also confirmed microscopically.

\section{Right ear from UT 1317}

On gross dissection, the inner ear was diffusely red black (Fig. 1a). Throughout the cochlear spiral, there was severe haemorrhage in the lumen as well as overlying and obscuring the apical aspect of the organ of Corti (Fig. 1a-c). In the most basal portion of the cochlea, a nematode parasite morphologically consistent with $S$. minor was identified (Fig. 1a,d-f). The extent of haemorrhage within the lumen of the cochlea precluded ultrastructural assessment of the inner and outer hair cells of the cochlear spiral by SEM.

\section{Left ear from UT 1317}

Histopathology of the left ear revealed no significant lesions (Fig. 2a-c). The changes in the stria vascularis, organ of Corti and supporting cells and tectorial membrane displacement were consistent with autolysis and sectioning artefact. At the lower apical turn of the cochlea, there was minimal luminal haemorrhage in the tympanic scala (Fig. 2d). Although a minor portion of the vestibule could not be evaluated, there was no evidence of cochlear helminthiasis in this ear.

\section{DISCUSSION}

This represents the index case of ectopic cochlear infection of Stenurus minor in a cetacean and in particular for harbour porpoises. S. minor was not observed in 128 ears examined from 74 harbour porpoises by histology, electron microscopy or immunofluorescence. An additional 47 harbour porpoise ears were used for establishing decalcification protocols (Morell et al. 2009) and, although the ears were not processed for optic or electron microscopy, there 

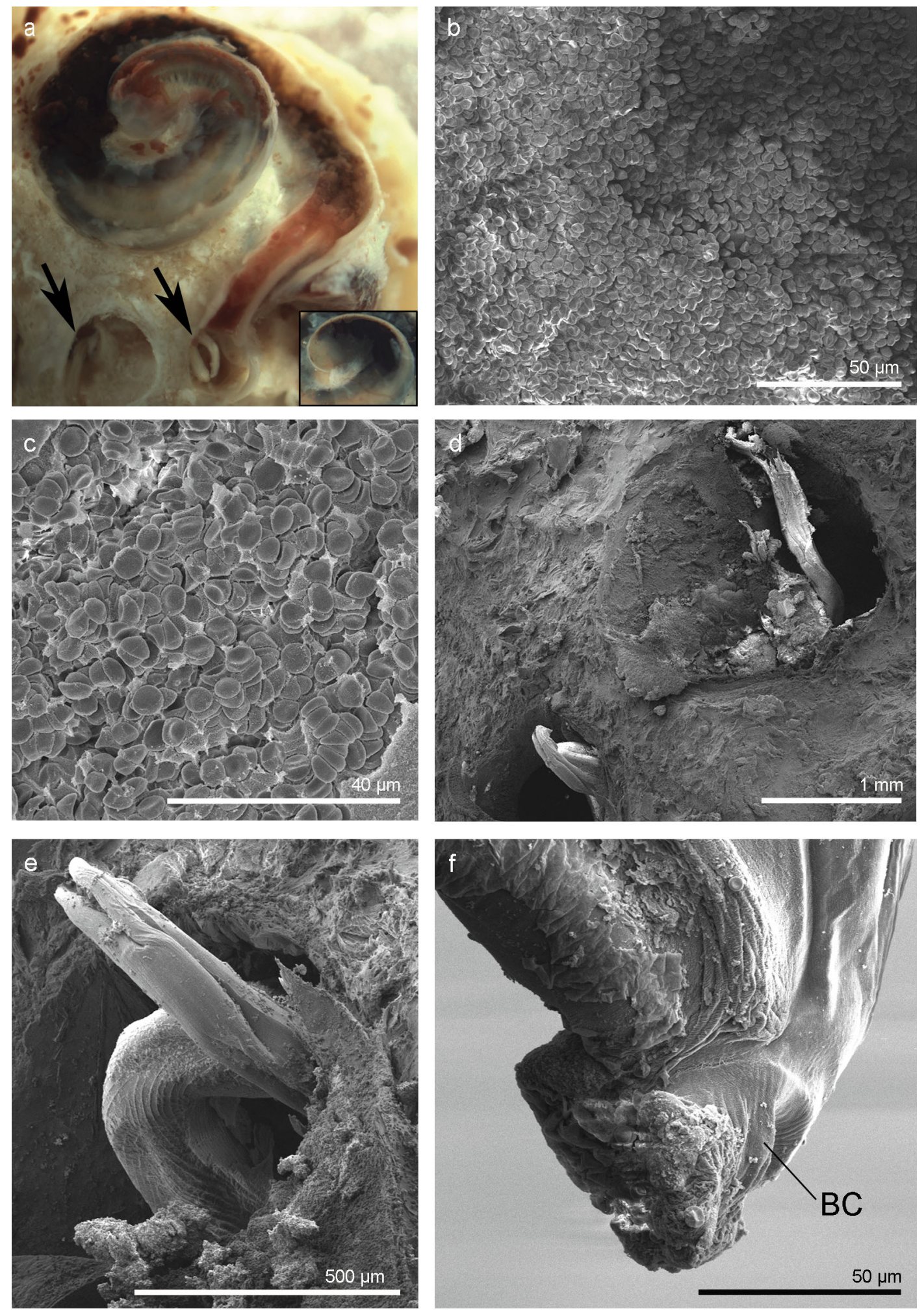

Fig. 1. Right ear from harbour porpoise Phocoena phocoena case UT 1317. (a) Gross image of the cochlea, showing severe haemorrhage with a solitary nematode morphologically consistent with Stenurus minor (arrows). Insert shows detail of the cochlear apex before further dissection. (b,c) Scanning electron microscopy of the cochlea with numerous extravasated erythrocytes at the lower basal turn and $(\mathrm{d}-\mathrm{f})$ exposed segment of a parasite at the lower basal turn and oval window.

(f) Caudal end of a male nematode, distinguished by the bursa copulatrix (BC) 


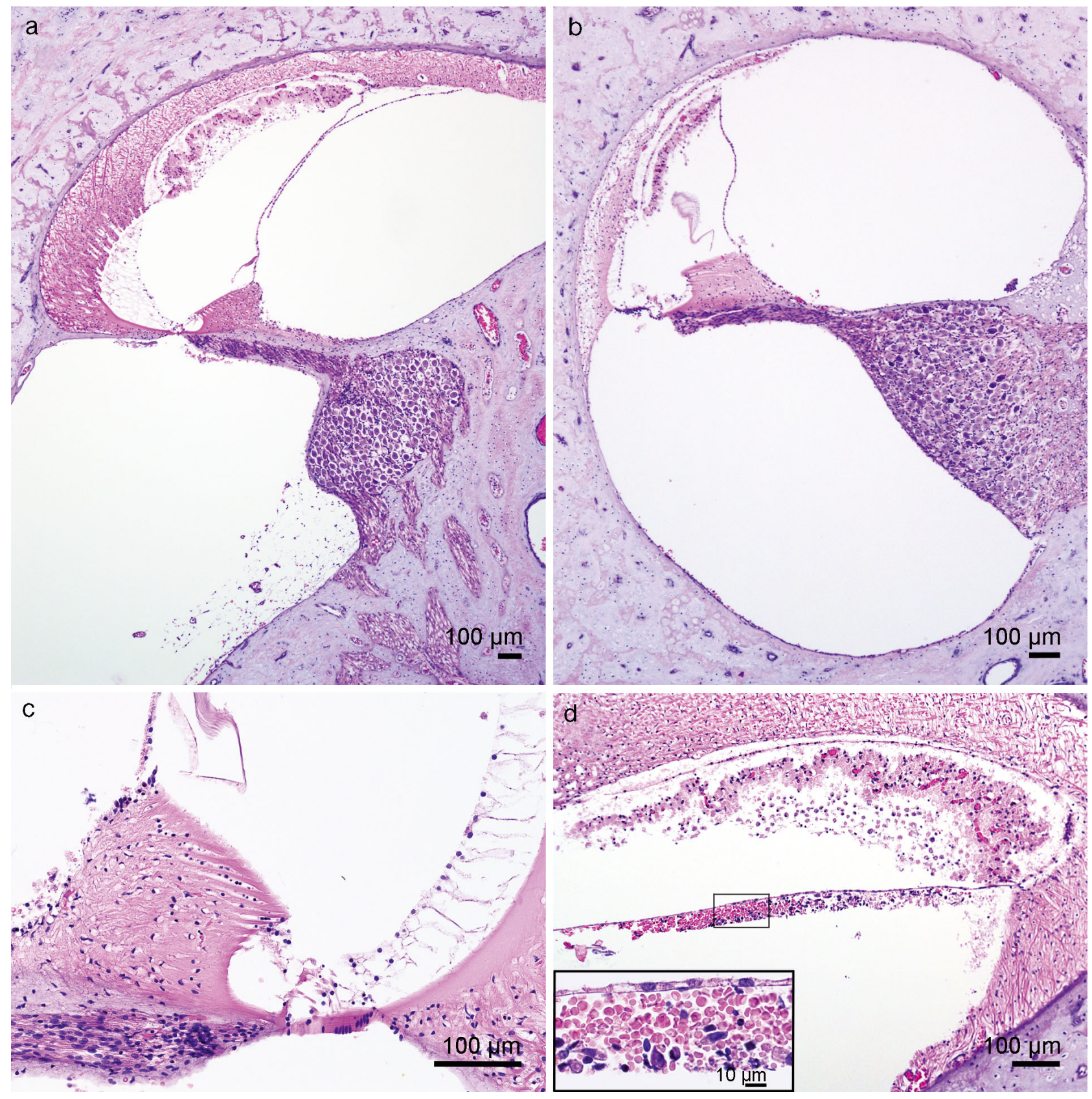

Fig. 2. Histology images of the left ear from harbour porpoise Phocoena phocoena case UT 1317. Organ of Corti of the (a,c) basal and (b) apical turns. (d) A small amount of acute haemorrhage is noted at the tympanic scala of the lower apical turn

were no parasites or associated haemorrhage observed on gross examination. Consequently, the involvement of $S$. minor in the cochlea of harbour porpoise is rare, with an incidence of $0.57 \%$ for our cases of Germany, Denmark and The Netherlands combined. Therefore, while the prevalence of $S$. minor in pterygoid and peribullar sinuses and tympanic cavity is high in harbour porpoises $(66.67 \%$ in our cases), its prevalence in the cochlea is rare.
In UT 1317, the acute haemorrhage was attributed to physical irritation of the organ of Corti caused by ectopic nematode parasite migration. The parasite likely penetrated from the tympanic cavity through the round window to access into the cochlea. Although cochlear haemorrhage may be related to anthropogenic activities, the lack of other systemic gross or microscopic lesions suggests ectopic parasite migration as the cause of this process. The haemor- 
rhage and intact cochlea confirm that parasite migration occurred ante-, rather than post mortem.

Since this individual was by-caught, the possibility of haemorrhage secondary to gas decompression type syndrome from rapid ascent in the net, blunt force trauma incurred on impact with the net or some other process cannot be excluded. In addition, haemorrhage in the inner ear may also be attributed to blast injury, degenerative and other disease processes. In human divers, spontaneous haemorrhage within the inner ear has been associated with haemorrhagic diathesis or coagulopathies (Schuknecht 1993).

The contribution of the cochlear infection due to the nematode as comorbidity and eventually to the animal's death remains unknown. Haemorrhages in the cochlea have been associated with cases of sudden sensorineural hearing loss in humans (Salomone et al. 2008). In addition, massive inner ear haemorrhage has been identified in humans as a cause for sudden deafness in cases associated with leukaemia (Schuknecht et al. 1965), Buerger's disease (Kirikae et al. 1962) or metastatic malignancy of the inner ear (Hoshino et al. 1972). Thus, in the case presented here, the infection of $S$. minor and haemorrhage overlying the organ of Corti (Fig. 1) may have impaired hearing in the right ear. There was recently ingested fish within the oral cavity, oesophagus and stomach, which suggests that the animal was able to successfully forage; however, since this was a by-caught animal, it cannot be excluded that the animal was not able to detect the gillnet. Since we do not have information on the time period of the parasitic presence in the cochlea, we should also consider the possibility that $S$. minor migrated to the inner ear during the struggling of the animal in the gillnet prior its death.

While there is still a current controversy on the effects of $S$. minor on the tympanic cavity (Dailey \& Walker 1978, Siebert et al. 2001, Kijewska et al. 2003), where the middle ear ossicles are located, our study shows that if the nematode parasite migrates to the inner ear, it would impair hearing.

The collection and analysis of the inner ear is not yet common practice among all stranding networks. This case highlights the need to investigate parasite infections, the effect of parasites on hearing and other pathological changes that might impair adequate processing of acoustic information, a fundamental process in cetaceans for their survival.

Acknowledgements. We thank Sandra Etheridge (Animal Health Center), José Manuel Fortuño (ICM-CSIC) and Derrick Horne (UBC Bioimaging Facility) for their invaluable technical assistance and Maria Hermus and Mariska Bijster- bosch for their help with the necropsy of this case. Special thanks go to the fisherman involved by landing this animal, which was done as part of the Remote Electronic Monitoring (REM) of incidental by-catch of harbour porpoises project by Wageningen Marine Research and Marine Science \& Communication. Both the REM project and the necropsies in The Netherlands are funded by Dutch Ministry of Economic Affairs. We thank all people involved in the stranding network in Schleswig-Holstein, Germany, Denmark and The Netherlands who helped to collect dead harbour porpoises, and we thank the veterinarians, biologists and technicians involved in the necropsies and further investigations on the animals. Samples were shipped from The Netherlands to Canada or Spain with appropriate CITES export and import permits and EU certificates. The inner ear analysis was supported by the 'Nederlandse Aardolie Maatschappij (NAM)', the Spanish Ministry of the Environment under contract 083/SDGTB/2007, Canadian Natural Sciences and Engineering Research Council Discovery and Accelerator grants RGPAS 446012-13 and RGPAN 312039-13. The stranding network and pathological investigations in SchleswigHolstein are partly funded by the Ministry of Energy, Agriculture, Environment and Rural Affairs of SchleswigHolstein, Germany. The investigations of the ear were funded by the German Federal Ministry of Food, Agriculture and Consumer Protection.

\section{LITERATURE CITED}

Arnold PW, Gaskin DE (1975) Lungworms (Metastrongyloidea: Pseudaliidae) of harbor porpoise Phocoena phocoena (L-1758). Can J Zool 53:713-735

* Brosens L, Jauniaux T, Siebert U, Benke H, Coignoul F (1996) Observations on the helminths of harbour porpoises (Phocoena phocoena) and common guillemots (Uria aalge) from the Belgian and German coasts. Vet Rec 139:254-257

*Bush AO, Lafferty KD, Lotz JM, Shostak AW (1997) Parasitology meets ecology on its own terms: Margolis et al. revisited. J Parasitol 83:575-583

* Dailey MD, Walker WA (1978) Parasitism as a factor (?) in single strandings of southern California cetaceans. J Parasitol 64:593-596

Deliamure S (1955) Helminthofauna of marine mammals; ecology and phylogeny. Academy of Sciences SSSR, Moscow

Faulkner J, Measures LN, Whoriskey FG (1998) Stenurus minor (Metastrongyloidea: Pseudaliidae) infections of the cranial sinuses of the harbour porpoise, Phocoena phocoena. Can J Zool 76:1209-1216

Hoshino T, Hiraide F, Nomura Y (1972) Metastatic tumor of the inner ear: a histological report. J Laryngol Otol 86: 697-707

Jepson PD, Prahl S, Deaville R, Siebert U (2006) Postmortem research feasibility study on cetacean ears. http: //randd.defra.gov.uk/Document.aspx?Document=WC04 008_4190_FRP.pdf (accessed 11 March 2013)

Kijewska A, Jankowski Z, Kuklik I, Rokicki J (2003) Pathological changes in the auditory organs of the harbor porpoise (Phocoena phocoena L.) associated with Stenurus minor (Kuhn, 1829). Acta Parasitol 48:60-63

Kirikae I, Nomura Y, Shitara T, Kobayashi T (1962) Sudden deafness due to Buerger's disease. Arch Otolaryngol 75: 502-505 
Kuiken T, García Hartmann MG (1993) Proceedings of the first European Cetacean Society workshop on cetacean pathology: dissection techniques and tissue sampling. Leiden, the Netherlands, 13-14 September 1991. ECS Newsl 17:1-39

Lehnert K, Raga JA, Siebert U (2005) Macroparasites in stranded and bycaught harbour porpoises from German and Norwegian waters. Dis Aquat Org 64:265-269

Lehnert K, Seibel H, Hasselmeier I, Wohlsein P and others (2014) Increase in parasite burden and associated pathology in harbour porpoises (Phocoena phocoena) in West Greenland. Polar Biol 37:321-331

Moore M, van der Hoop J, Barco S, Costidis A and others (eds) (2013) Criteria and case definitions for serious injury and death of pinnipeds and cetaceans caused by anthropogenic trauma. Dis Aquat Org 103:229-264

Morell M, André M (2009) Cetacean ear extraction and fixation protocol. www.zoology.ubc.ca/files/Ear_extraction and_fixation_protocol_UBC.pdf (accessed 7 Oct 2013)

Morell M, Degollada E, Alonso JM, Jauniaux T, Andre M (2009) Decalcifying odontocete ears following a routine protocol with RDO ${ }^{\circledR}$. J Exp Mar Biol Ecol 376:55-58

Morell M, Lenoir M, Shadwick RE, Jauniaux T and others (2015) Ultrastructure of the odontocete organ of Corti:

Editorial responsibility: Stephen Feist,

Weymouth, UK scanning and transmission electron microscopy. J Comp Neurol 523:431-448

Morell M, Brownlow A, McGovern B, Raverty SA, Shadwick RE, André $M$ (2017) Implementation of a method to visualize noise-induced hearing loss in mass stranded cetaceans. Sci Rep 7:41848

Salomone R, Abu TAA, Gonzaga-Chaves A, CundariBocalini MC, Oliveira-Vicente A, Riskalla PE (2008) Sudden hearing loss caused by labyrinthine hemorrhage. Rev Bras Otorrinolaringol 74:776-779 (in Portuguese)

Schuknecht HF (1993) Pathology of the ear, 2nd edn. Lea \& Febiger, Philadelphia, PA

Schuknecht HF, Igarashi M, Chasin WD (1965) Inner ear hemorrhage in leukemia: a case report. Laryngoscope 75:662-668

Siebert U, Wünschmann A, Weiss R, Frank H, Benke $H_{\text {, }}$ Frese K (2001) Post-mortem findings in harbour porpoises (Phocoena phocoena) from the German North and Baltic Seas. J Comp Pathol 124:102-114

Siebert U, Tolley K, Vikingsson GA, Olafsdottir D, Lehnert K, Weiss R, Baumgärtner W (2006) Pathological findings in harbour porpoises (Phocoena phocoena) from Norwegian and Icelandic waters. J Comp Pathol 134: $134-142$

Submitted: May 11, 2017; Accepted: September 11, 2017 Proofs received from author(s): November 3, 2017 